\title{
The Metabolism of Acetophenetidine
}

\section{ISOLATION AND CHARACTERIZATION OF $S$-(1-ACETAMIDO-4-HYDROXYPHENYL)- CYSTEINE, A METABOLITE OF ACETOPHENETIDINE}

\author{
By O. R. JAGENBURG AND K. TOCZKO* \\ Department of Medical Biochemistry, University of Gothenburg, Medicinaregatan 9, Gothenburg, Sweden
}

\author{
(Received 4 November 1963)
}

During studies of urinary amino acids on clinical material by O.R.J. a hitherto undescribed ninhydrin-positive compound was sometimes observed. The compound, which also gave a positive reaction with iodine-sodium azide reagent, indicating the presence of bivalent sulphur, was found to be of exogenic origin. It was demonstrable only in the urine of subjects dosed with fairly large quantities of acetophenetidine (phenacetin). According to Brodie \& Axelrod (1949) about $75 \%$ of an oral dose of acetophenetidine is excreted as conjugated $p$-acetamidophenol, about $4 \%$ as free $p$-acetamidophenol, less than $0.2 \%$ as unchanged acetophenetidine, and trace amounts as $p$-phenetidine. As none of these metabolites gives positive ninhydrin and iodine-azide reactions the compound observed must be a previously unknown metabolite of acetophenetidine. The present paper describes the isolation and partial characterization of this metabolite.

\section{EXPERIMENTAL}

Materials. $p$-Acetamidophenol and $p$-phenetidine were kindly supplied by Hoffmann-La Roche and Co. A.-G., Basel, Switzerland. $S$-p-Aminophenylcysteine was prepared as described by Boyland, Manson \& Nery (1962). Other compounds, including acetophenetidine, were of commercial origin.

Paper chromatography. Whatman no. 1 chromatography paper was employed for descending development in the solvent system (a) butan-1-ol-acetic acid-water (4:1:1, by vol.) and for ascending development in the system (b) phenol-water-aq. $\mathrm{NH}_{3}$ (sp.gr. 0.88) (800:200:1, by vol.). All runs were performed at $25^{\circ}$. When two-dimensional chromatograms were run the technique described by Jagenburg (1959) was used. For the detection of compounds on paper the following reagents were used: (1) ninhydrin $(0.2 \%, w / v)$ in butan-l-ol saturated with aq. $4 \mathrm{~N}$ acetic acid; (2) aq. $\mathrm{NaN}_{3}(0.5 \mathrm{M})-\mathrm{I}_{2}(0.01 \mathrm{M})$ plus $\mathrm{KI}(0.5 \mathrm{M})$ $\left(1: 1, \mathrm{v} / \mathrm{v}\right.$ ) (Sjöquist, 1953); (3) $0 \cdot 1 \mathrm{M}-\mathrm{K}_{2} \mathrm{Cr}_{2} \mathrm{O}_{7}$-acetic acid $(1: 1, v / v)$ followed by $\mathrm{AgNO}_{3}(0 \cdot 1 \mathrm{~m})$ (Knight \& Young $1958)$; (4) $\mathrm{Na}_{2} \mathrm{CO}_{3}(10 \%$, w/v) followed by diazotized sulphanilic acid [sulphanilic acid $(1 \%, \mathrm{w} / \mathrm{v}$, in $\mathrm{N} \cdot \mathrm{HCl}) \operatorname{mixed}$ with an equal volume of $\mathrm{NaNO}_{2}(5 \%, w / v)$ and allowed to stand for $5 \mathrm{~min}$.$] ; (5) \alpha$-naphthol $(1 \%, w / v)$ in $\mathrm{NaOH}$

* Present address: University of Warszawa, Department of Biochemistry, Warszawa, 22, W. Zwirki i Wigury 6, Poland.
$(8 \%, w / v) ;(6)$ diacetyl $(0 \cdot 1 \%)-\alpha$-naphthol $(1 \%)$ in $\mathrm{NaOH}$ $(8 \%, w / v)(1: 1, v / v)$. The method of Edman \& Sjöquist (1956) was used for the detection of compounds with absorption in the ultraviolet.

Electrometric titration. This was performed on a precision pH-meter (Radiometer pHM 4) equipped with a glass electrode (G 202 B) and a saturated calomel electrode (K 100). The titration was performed at $23^{\circ}$. Nitrogen, which had previously passed through $\mathrm{N}-\mathrm{H}_{2} \mathrm{SO}_{4}$ and $3 \mathrm{~N}$ $\mathrm{NaOH}$, was bubbled through the solution.

Hydrolysis. A portion (0.7 mg.) of the isolated compound was dissolved in $0.5 \mathrm{ml}$. of $1.0 \mathrm{~N}-\mathrm{HCl}$ and refluxed on a boiling-water bath. Every $5 \mathrm{~min}$. samples of the solution were taken for chromatography.

Oxidation. A sample (0.2 ml.) of a $0.27 \%$ solution of the isolated compound in water was mixed with $0.1 \mathrm{ml}$. of hydrogen peroxide and $0.1 \mathrm{ml}$. of $0.01 \mathrm{M}$-ammonium molybdate at room temperature. Samples of this mixture were immediately taken for chromatography.

Desulphurization. To $0.2 \mathrm{ml}$. of a $0.6 \%$ solution of the isolated metabolite in water was added a suspension containing 10-15 mg. of freshly prepared Raney nickel catalyst W-2 (Mozingo, 1955). The mixture was refluxed on a water bath for $30 \mathrm{~min}$. The supernatant solution was taken for chromatography.

Ultraviolet-absorption spectra. These were determined on a Cary recording spectrophotometer (model 14). The solvents used were $0.01 \mathrm{~N}-\mathrm{HCl}$ and $0.01 \mathrm{~N}-\mathrm{KOH}$. Quantitative determinations were performed on a Zeiss spectrophotometer (model PMQ II).

Infrared-absorption spectrum. This was recorded in potassium bromide, on a Perkin-Elmer Infracord spectrophotometer (model $137 \mathrm{~B}$ ).

Quantitative determination. A $10 \mathrm{ml}$. sample of urine, adjusted to $\mathrm{pH} 2$, was added to a column $(0.9 \mathrm{~cm} . \times 150 \mathrm{~cm}$.) of Amberlite IRC-120 (particle diam. 50-70 $\mu$ ) equilibrated with $0 \cdot 2 \mathrm{M}$-citrate buffer, $\mathrm{pH} 4 \cdot 25$. The elution was performed with the same buffer at $50^{\circ}$. Fractions $(2 \mathrm{ml}$.) were collected and the extinction at $295 \mathrm{~m} \mu$ was measured $\left(\epsilon_{295} 3000\right)$. The acetophenetidine metabolite to be determined was eluted between 220 and $240 \mathrm{ml}$. The ultravioletabsorption spectra of these fractions were identical with that of the isolated pure compound. On two occasions the fractions were simultaneously analysed by the ninhydrin method of Moore \& Stein (1954), with which the same results were obtained as by the ultraviolet-absorption method. The specificity of the method was further tested by examining the fractions paper-chromatographically (solvent 1) after first being desalted on a strong cation exchanger with $4 \mathrm{~N}-\mathrm{NH}_{3}$ as eluent. One part of the freezedried desalted material was hydrolysed in $\mathrm{N}-\mathrm{HCl}$ for $\mathbf{l ~ h r}$. at 
$100^{\circ}$ and a sample volume corresponding to $0.1 \mathrm{mg}$. of the metabolite was applied to each spot. The chromatograms were examined in the ultraviolet light and sprayed with location reagents $(1)-(6)$. No interfering substances were demonstrated either in the hydrolysed part of the sample or in the untreated part.

The recovery of the method was $99 \cdot 3 \%$ when a known amount of the purified compound was added to a normal urine which did not contain acetophenetidine metabolites. The fractions obtained between 220 and $240 \mathrm{ml}$. by chromatography of this urine did not contain substances absorbing at $295 \mathrm{~m} \mu$.

\section{RESULTS}

\section{Isolation of acetophenetidine metabolite}

Collection and pretreatment of urine. Twenty-four male students were given an oral dose of $2 \mathrm{~g}$. (four tablets) of acetophenetidine late in the evening and the urine was collected over $10 \mathrm{hr}$. The total volume of $6000 \mathrm{ml}$. was freeze-dried and then dissolved in $300 \mathrm{ml}$. of water. After the addition of $900 \mathrm{ml}$. of ethanol the solution was filtered and the precipitate discarded. The filtrate was diluted to $9000 \mathrm{ml}$. with water and divided into six $1500 \mathrm{ml}$. fractions.

Chromatography. The fractions were added to separate columns $(2 \mathrm{~cm} . \times 35 \mathrm{~cm}$.) of a strong cation exchanger (Amberlite IRC-120; $\mathrm{H}^{+}$form; 100200 mesh). The size of the columns were chosen so that about two-thirds of the capacity of the resin was used when the adsorption step was completed. The unknown metabolite was retained by the resin together with other ninhydrin-positive compounds in the urine. After washing with water the columns were eluted with $0 \cdot 05 \mathrm{M}$-citrate buffer, $\mathrm{pH} 4 \cdot 25$. The metabolite appeared together with $\beta$-aminoisobutyric acid and the aromatic amino acids, just after, but incompletely separated from, the neutral amino acids. It was completely separated from the basic amino acids. From each of the six runs the fraction containing the unknown metabolite (about $150 \mathrm{ml}$.) as judged from a positive iodine-sodium azide reaction was collected. The remaining fractions were discarded.

Rechromatography. The combined fractions (total volume $900 \mathrm{ml}$.) were rechromatographed with the ion-exchange chromatographic system described above. The size of the column was $1.5 \mathrm{~cm} . \times 50 \mathrm{~cm}$. The compound was eluted in a total volume of $160 \mathrm{ml}$. (16 fractions). As revealed by paper chromatography the first four of these fractions were contaminated with an unknown substance giving a positive reaction with the diacetyl- $\alpha$-naphthol reagent and with small amounts of tyrosine. The last six fractions contained also $\beta$-aminoisobutyric acid. The remaining six fractions, which were contaminated only with the diacetyl- $\alpha$-naphtholpositive substance, were used for further purification of the compound.
Crystallization. The combined fractions were desalted on a strong cation exchanger with $4 \mathrm{~N}$ ammonia as eluent. After evaporation in vacuo the dry residue was extracted with boiling ethanol under reflux to remove the contaminating diacetyl$\alpha$-naphthol-positive compound. The residue, which was still somewhat coloured, was dissolved in water and treated with small amounts of charcoal. The volume of the almost colourless filtrate was reduced by gentle heating on a water bath. After cooling the compound crystallized as clusters of small needles. The crystals were washed with water and ethanol, and after subsequent drying the yield was $104 \mathrm{mg}$. After renewed charcoal treatment and recrystallization colourless crystals were obtained, the yield being $48 \mathrm{mg}$. The product was chromatographically homogeneous.

\section{Characterization and identification of acetophenetidine metabolite}

The isolated compound was insoluble in organic solvents such as ether, chloroform, benzene and ethanol, slightly soluble in cold water and very soluble in alkali. It crystallized from water as clusters of colourless needles, m.p. 187-188 (uncorr.) (Found: C, 48.4; H, 5.3; N, 10.2; S, 11.7 . Calc for $\mathrm{C}_{11} \mathrm{H}_{14} \mathrm{~N}_{2} \mathrm{O}_{4} \mathrm{~S}: \mathrm{C}, 48 \cdot 9 ; \mathrm{H}, 5 \cdot 2 ; \mathrm{N}, 10 \cdot 4 ; \mathrm{S}$, $11.9 \%)$. Electrometric titration of the isolated compound showed one titratable group in the acid range and two groups in the alkaline. The molecular weight, calculated on the basis of the titration data, was about 270 assuming two titrable groups in the alkaline range. The $\mathrm{pH}$ of a solution containing $5.27 \mathrm{mg}$. of the compound in $10 \mathrm{ml}$. of $0.15 \mathrm{M}$ potassium chloride was $6 \cdot 27$. By paper ionophoresis in veronal buffer, $\mathrm{pH} 8 \cdot 6$, and in phosphate buffers, pH 5.9 and $6 \cdot 8$, the compound migrated as a neutral amino acid. By ion-exchange chromatographic analysis according to the method of Moore, Spackman \& Stein (1958) the compound was eluted just after, but well separated from, tyrosine. The infrared-absorption spectrum indicates the presence of amino groups (absorption band at $6 \cdot 2 \mu$ ) as well as monosubstituted amides (absorption bands at 6.0 and $6.5 \mu$ ). The ultraviolet-absorption spectrum $\left(\lambda_{\max } .203,243\right.$ and $295 \mathrm{~m} \mu$ at $\mathrm{pH} 2$, and 270 and $313 \mathrm{~m} \mu$ at $\mathrm{pH} 13$ ) was characteristic for substituted aromatic compounds. The shift in alkaline medium of the $295 \mathrm{~m} \mu$ band to $313 \mathrm{~m} \mu$ indicated the presence of a free phenolic hydroxyl group. The existence of this group was also supported by a positive reaction with diazotized sulphanilic acid (red-brown).

The isolated compound gave the same reaction with ninhydrin on paper as did most $\alpha$-amino acids, i.e. a purple colour developed after less than $1 \mathrm{hr}$. at room temperature. When the ninhydrin reaction was performed in solution as described by Moore \& 
Table 1. Reactivity of the isolated acetophenetedine metabolite and its reaction products after hydrolysis and oxidation as compared with S-p-aminophenylcysteine and p-aminophenol when detected on paper chromatograms with different reagents

Experimental details are given in the text.

$R_{F}$ in solvent $(a)$

$R_{F}$ in solvent $(b)$

Ninhydrin

Iodine-azide

$\mathrm{K}_{2} \mathrm{Cr}_{2} \mathrm{O}_{7}+\mathrm{AgNO}_{3}$

Diazotized sulphanilic acid

$\alpha$-Naphthol in alkali

Ultraviolet absorption
Isolated compound

\begin{tabular}{|c|c|c|c|c|}
\hline Untreated & $\begin{array}{l}\text { After hydrolysis } \\
\text { in N-HCl at } \\
100^{\circ} \text { for } 30 \mathrm{~min} \text {. }\end{array}$ & $\begin{array}{c}\text { After oxidation } \\
\text { with } \mathrm{H}_{2} \mathrm{O}_{2} \text { plus } \\
\text { ammonium } \\
\text { molybdate }\end{array}$ & $\begin{array}{l}S-p \text {-Aminophenyl- } \\
\text { cysteine }\end{array}$ & $\begin{array}{c}p \text {-Amino- } \\
\text { phenol }\end{array}$ \\
\hline $\begin{array}{l}0.27 \\
0 \cdot 70\end{array}$ & $\begin{array}{l}0.08 \\
0.53\end{array}$ & $\begin{array}{l}0 \cdot 19 \\
0 \cdot 47\end{array}$ & $\begin{array}{l}0.24 \\
0 \cdot 73\end{array}$ & $\begin{array}{l}0.64 \\
0.95\end{array}$ \\
\hline Purple & $\begin{array}{l}0.33 \\
\text { Brown-purple }\end{array}$ & Brown-purple & Purple & Brown \\
\hline Positive & Positive* & Negative & Positive & Negative* \\
\hline Positive & Positive & Negative & Positive & Negative \\
\hline Red-brown & Grey-green & Negative & Negative & Blue-grey \\
\hline Negative & Bluet & Negative & Negative & Blue $†$ \\
\hline Positive & Positive & Positive & Positive & Positive \\
\hline
\end{tabular}

* After some minutes a stable brown colour appeared, due to a reaction with $\mathrm{NaN}_{3}$.

$\dagger$ Immediately after spraying, and without heating, an intense stable blue colour appeared. The colour turned red when the spot was exposed to the vapour of conc. $\mathrm{HCl}$.

Stein (1954) the extinction at $570 \mathrm{~m} \mu$ was $99 \%$ of that given by leucine on molar basis (assuming the molecular weight to be 270).

The presence of bivalent sulphur in the isolated compound was demonstrated by its reaction with the iodine-sodium azide and potassium dichromate-silver nitrate reagents. After oxidation only one compound was obtained with lower $R_{F}$ values in solvents $(a)$ and $(b)$ than the untreated compound (Table 1). It could be located on the chromatogram by ultraviolet light (Edman \& Sjöquist, 1956) or by ninhydrin, but gave negative reactions with iodine-sodium azide and potassium dichromatesilver nitrate reagents, indicating a transformation of the originally bivalent sulphur into a higher oxidation state.

The isolated untreated compound could easily be hydrolysed in acid medium; even after a few minutes in N-hydrochloric acid at $100^{\circ}$ a ninhydrinpositive degradation product was observed on paper chromatograms. After $30 \mathrm{~min}$. the hydrolysis was complete. The compound obtained had lower $R_{F}$ values in solvents $(a)$ and $(b)$ than did the original compound (Table 1 ) and gave positive reactions with iodine-sodium azide, potassium dichromate-silver nitrate and diazotized sulphanilic acid reagents. In contrast with the untreated compound the compound obtained after hydrolysis gave a very characteristic reaction with $\alpha$-naphthol in alkaline medium. Immediately after spraying, and without heating the chromatogram, an intense blue colour developed, which was probably due to the formation of an indophenol dye (cf. Brodie \& Axelrod, 1948). The colour turned red when the spot was exposed to the vapour of conc. hydrochloric acid. The same reaction was obtained with $p$-aminophenol, whereas $p$-acetamidophenol, $p$-phenetidine, $o$-aminophenol, $m$-aminophenol, aniline and $S$-p-aminophenylcysteine did not react in this way. As judged from the experiments performed this reaction seems to be specific for compounds containing a free amino group and a free hydroxyl group in the para-position. The product obtained after hydrolysis thus probably contains this structure, whereas in the natural metabolite the aromatic group is blocked.

Desulphurization of the isolated compound with Raney nickel, as revealed from paper chromatography, gave a complete degradation into alanine and $p$-acetamidophenol. No further degradation products were chromatographically demonstrable.

All the data obtained suggested that the isolated metabolite of acetophenetidine was $S$-(1-acetamido4-hydroxyphenyl)cysteine. A linkage of the $\mathrm{S}$ to the acetamido $\mathrm{N}$ seems less likely, as the infraredabsorption spectrum showed a strong band at $6.5 \mu$ which is characteristic of monosubstituted amides whereas disubstituted amides do not give this band.

\section{Excretion of \\ S-(1-acetamido-4-hydroxyphenyl)cysteine}

In three healthy male subjects given $2 \mathrm{~g}$. of acetophenetidine orally the excretion over $24 \mathrm{hr}$. corresponded to $1.9,2.0$ and $2.1 \%$ of the dose given.

\section{Experiments with p-acetamidophenol}

A male subject was dosed with $2 \mathrm{~g}$. of $p$-acetamidophenol and the urine was collected over $24 \mathrm{hr}$. in two separate portions. The first portion corresponding to a 10-hr. sample was analysed as described under the heading 'Quantitative deter- 
mination'. A compound with the same ultravioletabsorption spectrum as the compound supposed to be $S$-(1-acetamido-4-hydroxyphenyl)cysteine was eluted between 220 and $240 \mathrm{ml}$. These fractions were desalted and the material obtained was analysed by paper chromatography. Thereby a compound was demonstrated which had the same $R_{F}$ values and the same colour reactions as the isolated metabolite of acetophenetidine (compare Table 1). The amount of the compound in the first portion corresponded to $1.9 \%$ of the dose given and in the second portion to $0.9 \%$. The excretion over $24 \mathrm{hr}$. thus corresponded to $2 \cdot 8 \%$ of the dose.

\section{DISCUSSION}

Since Baumann \& Preusse (1879) and Jaffé (1879) showed that the administration of monohalogenated benzenes to dogs led to the excretion of $N$-acetylcysteine derivatives (mercapturic acids), many other aromatic hydrocarbons have been found to be metabolized in a similar way (ef. Williams, 1959). More recent works show that in several species aromatic amines (Boyland, Manson \& Nery, 1963) as well as certain aliphatic compounds (Thomson, Maw \& Young, 1958; Bray \& James, 1958) are also transformed into mercapturic acids. The formation of mercapturic acids thus appears to be a general metabolic pathway not restricted entirely to aromatic compounds.

Although the metabolism of acetophenetidine has been investigated both in man (Brodie \& Axelrod, 1949) and in the rabbit (Smith \& Williams, 1949) the formation of a cysteine derivate does not appear to have been described. However, as shown from the present study in man, about $2 \%$ of the drug is excreted as $S$-(1-acetamido-4hydroxyphenyl)cysteine. In the formation of this metabolite it seems probable that acetophenetidine (I) is first de-ethylated to $p$-acetamidophenol (II), and then conjugated with cysteine to the final metabolite (III). $p$-Acetamidophenol given orally forms the same metabolite (III). Preliminary experiments have shown that there is also an excretion of 1-acetamido-4-hydroxyphenylmercapturic acid (IV), but this excretion seems to be low.

Substances known to be detoxified by conjugation with cysteine are believed to be excreted as the corresponding mercapturic acids. This is in agreement with the observation that in most species, including man (Stekol, 1946), arylcysteines are readily transformed into mercapturic acids (cf. Williams, 1959). The only animal reported to have a low capacity to acetylate aliphatic amino groups is the guinea pig (Bray, Franklin \& James, 1958). As shown from the present study, however, the aliphatic amino group of $S$-(1-acetamido-4-hydroxyphenyl)cysteine is but incompletely acetylated in man, in spite of the fact that only a small part of the $p$-acetamidophenol formed is conjugated with cysteine. Whether other compounds detoxified by conjugation with cysteine are also excreted as the corresponding unacetylated cysteine derivative, or whether they are as a rule completely transformed into the mercapturic acid, does not seem to have been studied previously.

\section{SUMMARY}

1. A new metabolite of acetophenetidine (phenacetin), which is $S$-(1-acetamido-4-hydroxyphenyl)cysteine, has been detected in and isolated from human urine.

2. After the oral administration of $2 \mathrm{~g}$. of acetophenetidine $2 \%$ of the dose is excreted as this metabolite within $24 \mathrm{hr}$.

This work was aided by a grant from the Medical Faculty, University of Gothenburg.

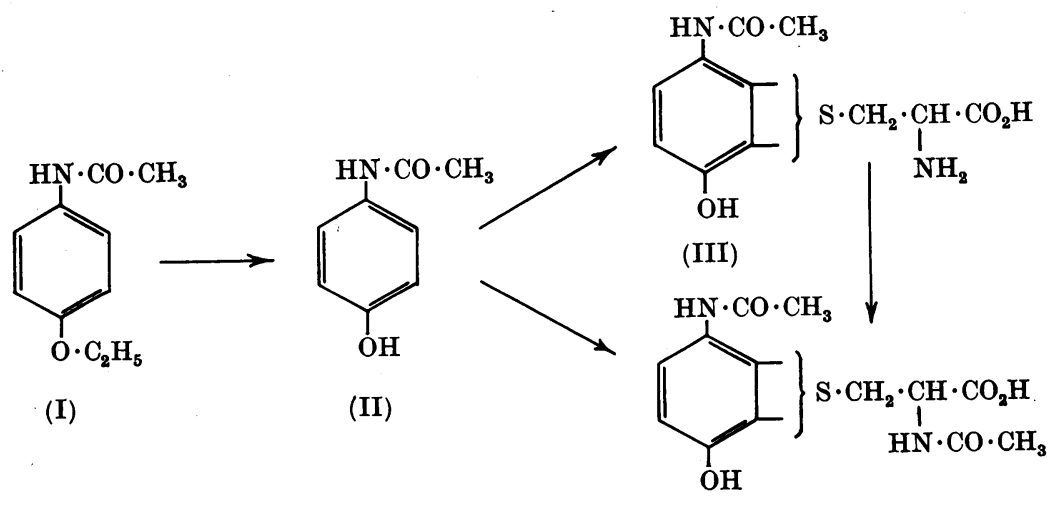

(IV) 


\section{REFERENCES}

Baumann, E. \& Preusse, C. (1879). Ber. dtsch. chem. Ges. $12,806$.

Boyland, E., Manson, D. \& Nery, R. (1962). J. chem. Soc. p. 606.

Boyland, E., Manson, D. \& Nery, R. (1963). Biochem.J.86, 263.

Bray, H. G., Franklin, T. J. \& James, S. P. (1958) Biochem. J. 69, 4 P.

Bray, H. G. \& James, S. P. (1958). Biochem. J. 69, 24 P.

Brodie, B. B. \& Axelrod, J. (1948). J. Pharmacol. 94, 22.

Brodie, B. B. \& Axelrod, J. (1949). J. Pharmacol. 97, 58.

Edman, P. \& Sjöquist, J. (1956). Acta chem. scand. 10, 1507.
Jaffé, M. (1879). Ber. dtsch. chem. Ges. 12, 1092.

Jagenburg, O. R. (1959). Scand. J. clin. Lab. Invest. 11 (suppl.), 43.

Knight, R. H. \& Young, L. (1958). Biochem. J. 70, 111.

Moore, S., Spackman, D. H. \& Stein, W. H. (1958). Analyt. Chem. 30, 1185.

Moore, S. \& Stein, W. H. (1954). J. biol. Chem. 211, 907.

Mozingo, R. (1955). In Organic Syntheses (Collective Volumes), vol. 3, p. 181.

Sjöquist, J. (1953). Acta chem. scand. 7, 447.

Smith, J. N. \& Williams, R. T. (1949). Biochem. J. 44, 239.

Stekol, J. A. (1946). J. biol. Chem. 164, 651.

Thomson, A. E. R., Maw, G. A. \& Young, L. (1958). Biochem. J. 69, 23 P.

Williams, R.T. (1959). Detoxication Mechanisms, pp. 8, 237-250. London: Chapman and Hall Ltd.

Biochem. J. (1964), 92, 643

\title{
Reactions of 6-Aminopenicillanic Acid with Carbohydrates and Related Substances
}

\author{
By M. O. MOSS AND M. COLE \\ Beecham Research Laboratories, Research Division, Betchworth, Surrey
}

(Received 14 January 1964)

The amino group of 6-APA* is involved in many reactions that occur in aqueous solution at room temperature and neutral pH. Grant, Clark \& Alburn (1962) reported the formation of large polymers in very concentrated solutions of 6-APA, whereas Batchelor, Cole, Gazzard \& Rolinson (1962), working with less concentrated solutions, showed the presence of several compounds of smaller molecular weight. 6-APA undergoes a ready reaction with carbon dioxide through its amino group followed by a molecular rearrangement to 8-hydroxypenillic acid (Batchelor, Gazzard \& Nayler, 1961; Johnson \& Hardcastle, 1961). The product of this reaction was identified in, and isolated from, the fermentation liquors of Penicillium chrysogenum by Ballio et al. (1961). It is known that 6-APA forms anil-like compounds with aromatic aldehydes, and the preparation of such an anil with 2-hydroxynaphthaldehyde has been reported by Wolfe, Godfrey, Holdrege \& Perron (1963).

During experiments involving the addition of 6-APA to growing cultures of fungi the present authors observed a number of phenomena that were found to involve the reaction of the primary amino group of 6-APA with mould metabolites and components of the fermentation media. These reactions can be broadly classified into two groups, one in-

* Abbreviation: 6-APA, 6-aminopenicillanic acid. volving reducing sugars, the other involving complex carbonyl compounds produced by some fungi. The present paper is concerned with the first group of compounds. The preparation and isolation of compounds thought to be $N$-glucosyl, $N$-maltosyl and $N$-lactosyl derivatives of 6-APA are also described.

\section{METHODS}

Assay of glycosyl-6-aminopenicillanic acid, 'total nucleus' and free 6-aminopenicillanic acid. Because most of the derivatives of sugars and 6-APA were found to be stable to penicillinase they could be assayed as the difference between the assay for free 6-APA (penicillinase-labile material) and total 6-APA ( $\mathrm{NaOH}$-labile), referred to below as 'total nucleus'. The total nucleus was assayed in reaction mixtures by the hydroxylamine method described by Batchelor, Chain, Hardy, Mansford \& Rolinson (1961). Free 6-APA was assayed by the same procedure by using $0.5 \mathrm{ml}$. of a $20 \%$ solution of Bacillus cereus penicillinase instead of $\mathrm{NaOH}$ for the blank (Batchelor, Cameron-Wood, Chain \& Rolinson, 1961). Penicillinase was prepared by the method of Pollock (1957) with the organism Bacillus cereus N.C.T.C. 9946.

Chromatography. Descending chromatography was carried out overnight at $5^{\circ}$ on sheets and also on $1 \mathrm{~cm}$.-wide tapes of Whatman no. 1 paper with the solvent system butan-1-ol-pyridine-water (1:1:1, by vol.). Reducing sugars, 6-APA and the compounds of the two were detected by dipping chromatograms in an acetone solution of $\mathrm{AgNO}_{3}$, drying and spraying with ethanolic $\mathrm{NaOH}$. After 